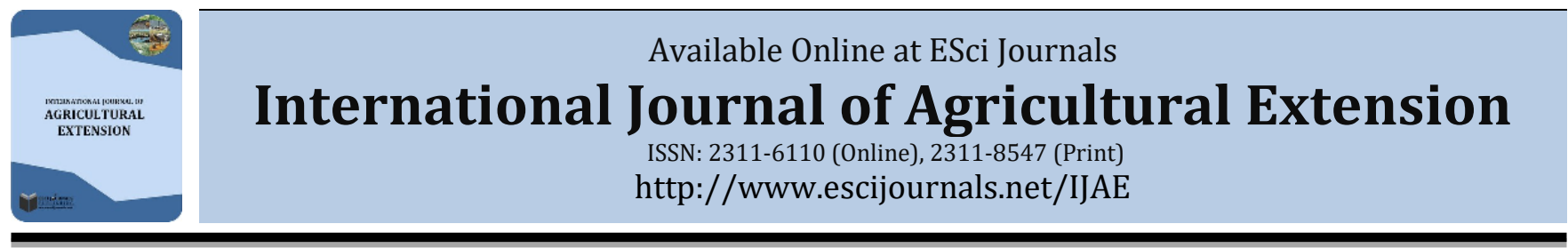

\title{
THE FLOATING TRADITIONAL RICE TECHNO-DEMONSTRATION FOR COMMUNITY FOOD SECURITY
}

\author{
Pasigan U. Buisan*, Nasrudin A. Buisan \\ Cotabato City State Polytechnic College, Cotabato City, Philippines.
}

\section{A B S T R A C T}

Rice ranks as the most important cereal in the Philippines. It is one of the country's largest agricultural production systems, highest among crop production. The general objective of the study was to determine if traditional rice variety can give optimum yield when planted in the floating area. The materials used were traditional rice varieties. The water hyacinth was converted into a rice floating area. Data gathered was analyzed using the analysis of variance. The LSD Test was employed to compare the significant difference between treatment mean values. Floating rice production is a viable option among small farmers particularly in areas where water availability is not controlling such as marshy area. Local materials such as water hyacinth as floater are widely available. There is a need however, for a sound cultural management to make it sustainable. The good agronomic characteristics of the rice varieties can be attributed by the types of variety and the management practices. The floating area can be converted a potential area for rice production for a certain community particularly in the marshy area. However, there a need for a sound management practices in the floating area that can farmers may adopt for a sustainable rice floating production area.

Keywords: Floating Traditional Rice, Community Food Security.

\section{INTRODUCTION}

Rice ranks as the most important cereal in the Philippines. It is one of the country's largest agricultural production systems. In 2014, rice production grew at $2.87 \%$., highest among other crops. It contributed more than P378 billion in the same year (Philippine Statistics Authority, 2015). Since there are areas which do not yet favorable to rice production like marshy area people could hardly sustain their staple food. In the Philippines there are areas which contain marshy. This form of marsh is defined by the fact that, although it is a freshwater marsh, it is still affected by the tides. Without the stresses of salinity that are undergone by its salt water counterpart, the diversity of the plants and animals that live in and use these marshes is much higher than in salt marshes. The most serious threats to this form of marsh are the increasing size and pollution of the places surrounding them (Wikipedia, 2016). It is also noted that one of the most plants found in marshy area is the water hyacinth. Water hyacinth is a

* Corresponding Author:

Email: pasbuisan@yahoo.com

(C) 2019 ESci Journals Publishing. All rights reserved. free-floating perennial plant that can grow to a height of 3 feet. The dark green leave blades are circular to elliptical in shape attached to spongy, inflated petiole. Underneath the water is a thick, heavily branched, dark fibrous root system. The water hyacinth has striking light blue violet flowers located on a terminal spike. Water hyacinth is very aggressive invader and can form thick mats. If these mats cover the entire surface of the pond they cause oxygen depletions and fish kills. Water hyacinth should be controlled so they can not cover the entire pond. Submerged portions of all aquatic plants provide habitats for many micro and macro invertebrates. These invertebrates in turn are used as food by fish and other wildlife species (e.g. amphibians, reptiles, ducks, etc.). After aquatic plants die, their decomposition by bacteria and fungi provide food (called "detritus" for many aquatic invertebrates. Water hyacinth has no known direct food value to wildlife and is considered a pest species (Texas A\& M AgriLife Extension Services, 2016). Hence, study on determining whether water hyacinth area can convert to a floating rice production for a community sustainable food security was conceptualized. 
Objectives of the Study: The general objective of the study was to determine if rice can give optimum yield when planted in the floating area. Specifically, the study aimed;

- To find out which among the varieties can give high yield?

- To find out the significant difference among the varieties in their agronomic characteristics.

- To find out whether floating area can be utilizing for rice production.

\section{MATERIAL AND METHODS}

The materials used in the study were the three rice varieties such as: (Tanggiling, Kawilan, and NSICRc 224). The study was conducted in Marshy area of Maguindanao Province, particularly in Datu Salibo. Randomized Complete Block Design with three treatments replicated three times was used and LSD for the test of significant. The water hyacinth were converted to production area by reverted upward the roots and the leaves downward underneath for planting space. Standard cultural practices in rice were observed.

Data were collected on the following agronomic parameters such as;

Plant height: The height $(\mathrm{cm})$ of the rice plant was measured from the base to the tip of the tallest leaf of ten sample plants per plot, taken at random before harvesting.

Number of productive tillers per hil:. This was done by counting the number of tillers with panicle per hill from
10 hills per plot taken at random.

Number of unproductive tillers per hill: This was done by counting the number of tillers without panicle per hill from 10 hills per plot taken at random.

Length (cm) of panicle: This was taken from ten samples per plot taken random before harvest. This was measured from the panicle neck to the tip.

Percentage of filled grains: This was done by counting the total number of filled grains per panicle from ten samples per plot and was computed using the formula.

$$
\% \text { filled and grains }=\frac{\text { Total no. of filled }}{\text { Total no. of sample grains }} \times 100
$$

Percentage of unfilled grains: This was be done by counting the total number of unfilled grains per panicle per panicle from ten samples per plot and was computed using the formula.

$$
\% \text { unfilled grains }=\frac{\text { Total no. of unfilled grains }}{\text { Total no. of sample grains }} \times 100
$$

Weight (g) of 1000 dry grains: One thousand grains per treatment were weighed after drying at $14 \%$ moisture content.

Grain yield ( $t / \mathbf{h a}$ ): The fresh yield of rice was taken after harvesting and using the following formula;

$$
\text { Grain Yield }=\frac{\text { Grain wt }(\mathrm{Kg}) / \text { Treatment } / \text { Sample Area }}{\text { Sample area/Treatment }}: \frac{\text { Grain wt }(\mathrm{Kg} / \mathrm{ha})}{\text { Area }}
$$

Statistical Analysis: Data gathered were analyzed using the analysis of variance (ANOVA). The Least Significant Difference (LSD) test was employed to compare the significant difference between or among treatment mean values.

\section{RESULTS AND DISCUSSION}

Plant Height (cm): On the plant height, statistical analysis revealed that among the varieties, Tanggiling varieties was the tallest variety with its mean of 127.42 $\mathrm{cm}$, followed by Kawilan with its mean of $126.58 \mathrm{~cm}$, and, the shortest variety was the NSIC Rc 224 with its mean of $101.38 \mathrm{~cm}$. Result indicates that really the Tanggiling were the tallest varieties.

Number of Productive Tiller: There were significant differences on the number of productive tillers. NSIC Rc 224 variety had the highest number of productive tillers with their mean of 17.215 , followed by Tanggiling $(16.48 \%)$ and Kawilan (16.43\%). Results indicate that a NSIC Rc 224 is truly adaptable to floating areas. This is probably anchored on the report of PhilRice (2006) that plants with high numbers of tiller are more likely to have greater spread of grain size which results to an increase of yield.

Number of Unproductive Tiller: On the number of unproductive tillers, NSICRc 224 had the lowest number of unproductive tillers (3.70\%), followed by Tanggiling (3.83\%) and the highest number of unproductive tillers was recorded in the Kawilan variety (4.33\%). Results indicate that the NSIC Rc 224 had strong adaptability to 
floating areas.

Percentage of Filled Grain: Results revealed that there were also significant difference percentages of filled grains. NSIC Rc 224 obtained the highest percentage of filled grains with a mean of 95.415 and were comparable with the Tanggiling varieties with its mean of $95.22 \%$. Tanggiling with a mean of $94.88 \%$ is comparable to Kawilan. Results indicate that NSIC Rc 224 is really adaptable to floating area and so are the other cultivars.

Percentage of Unfilled Grains: The same manner, statistical analysis reveals that among the varieties exhibited significant difference. Kawilan varieties registered the highest percentage of unfilled grains with its mean of $5.12 \%$ and is comparable with Tanggiling which had a mean of 4.78. Results indicate that Kawilan variety is also adaptable to floating area and so are the other varieties.
Length of Panicle (cm): Results also revealed that among varieties, the Kawilan variety had the longest length of panicle with its mean of $25.96 \%$, followed by the Tanggiling with its mean of $25.79 \%$ and the NSIC Rc 224 with a mean of $25.29 \%$.

Grain Yield (ton/ha): Further, statistical analysis reveals that among the varieties exhibited significant difference. The yield of NSIC Rc 224 was the heavier weight with a mean of 3.72, followed byKawilan (3.57) and Tanggiling (3.51).

This indicates that the NSIC Rc 224 is really heavier compared with other varieties. This is also congruent with the PHIRICE report that, usually the weight of rice under saline areas ranges from 3.5 to 5 ton per hectare. In fact, traditional variety has characteristics of resistance to disease.

Table 1. Agronomic characteristics of traditional rice varieties planted in the floating area.

\begin{tabular}{llllllll}
\hline Factor & \multicolumn{1}{c}{ PH } & \multicolumn{1}{c}{ PT } & \multicolumn{1}{c}{ UT } & FG & UG & LP & Y(th-1) \\
\hline Tanggiling & $127.42^{\mathrm{a}}$ & $15.48^{\mathrm{b}}$ & $3.83^{\mathrm{b}}$ & $95.22^{\mathrm{ab}}$ & $4.78^{\mathrm{ab}}$ & $25.79^{\mathrm{a}}$ & $3.51^{\mathrm{c}}$ \\
Kawilan & $126.58^{\mathrm{b}}$ & $15.43^{\mathrm{c}}$ & $4.33^{\mathrm{a}}$ & $94.88^{\mathrm{b}}$ & $5.12^{\mathrm{a}}$ & $25.96^{\mathrm{a}}$ & $3.57^{\mathrm{b}}$ \\
NSIC Rc 224 & $101.38^{\mathrm{c}}$ & $16.21^{\mathrm{a}}$ & $3.70^{\mathrm{b}}$ & $95.41^{\mathrm{a}}$ & $4.59^{\mathrm{b}}$ & $25.29^{\mathrm{b}}$ & $3.72^{\mathrm{a}}$ \\
C.v. & 2.52 & 1.81 & 19.57 & 0.66 & 12.95 & 1.58 & 0.16 \\
\hline
\end{tabular}

Treatment followed the same superscripts are not significantly difference.

PH-Plant height PT-Productive tiller; UT- Unproductive tiller

FG-Filled grains, UG-Unfilled grains; LP-Length of panicle; Y (t h-1)- Yield ton/hectare.

\section{CONCLUSION AND RECOMMENDATIONS}

The agronomic characteristics of the rice varieties can be attributed by the types of variety and the management practices. The floating area can be converted a potential area for rice production for a certain community particularly in the marshy area. There is a need for a sound management practices in the floating area that can farmers may adopt for a sustainable rice floating production area.

\section{REFERENCES}

Philippine Statistics Authority. (2015). Selected Statistics on Agriculture 2015. Quezon City: Philippine Statistics Authority.

Texas A\& M AgriLife Extension Services. (2016). Water Hyacitnh. Dipetik July 26, 2016, dari Aquaplant: http://aquaplant.tamu.edu/plantidentification/alphabetical-index/waterhyacinth/. 